\title{
Psychobehavioural Factors Are More Strongly Associated with Successful Weight Management Than Predetermined Satiety Effect or Other Characteristics of Diet
}

\author{
Leila Karhunen, ${ }^{1}$ Marika Lyly, ${ }^{2,3}$ Anja Lapveteläinen, ${ }^{1}$ Marjukka Kolehmainen, ${ }^{1}$ \\ David E. Laaksonen, ${ }^{4,5}$ Liisa Lähteenmäki, ${ }^{2,6}$ and Kaisa Poutanen ${ }^{1,2}$ \\ ${ }^{1}$ Department of Clinical Nutrition, Food and Health Research Centre, Institute of Public Health and Clinical Nutrition, \\ University of Eastern Finland, Kuopio Campus, P.O. Box 1627, 70211 Kuopio, Finland \\ ${ }^{2}$ VTT Technical Research Centre of Finland, P.O. Box 1000, 02044 Espoo, Finland \\ ${ }^{3}$ Vaasan Oy, P.O. Box 250, 02631 Espoo, Finland \\ ${ }^{4}$ Department of Medicine, Kuopio University Hospital, P.O. Box 1777, 70211 Kuopio, Finland \\ ${ }^{5}$ Institute of Biomedicine, Physiology, University of Eastern Finland, Kuopio Campus, P.O. Box 1627, 70211 Kuopio, Finland \\ ${ }^{6}$ MAPP, Department of Business Administration, Business and Social Sciences, Arhus University, Haslegaardsvej 10, 8210 Arhus V, \\ Denmark
}

Correspondence should be addressed to Leila Karhunen, leila.karhunen@uef.fi

Received 8 November 2011; Revised 5 March 2012; Accepted 16 April 2012

Academic Editor: Simone Lemieux

Copyright (C) 2012 Leila Karhunen et al. This is an open access article distributed under the Creative Commons Attribution License, which permits unrestricted use, distribution, and reproduction in any medium, provided the original work is properly cited.

\begin{abstract}
This study aimed to investigate factors associated with weight management, especially whether satiety value of food as a part of a weight-maintenance diet would affect self-regulation of food intake and weight management. Altogether 82 obese subjects completed the study consisting of weight-loss and weight-maintenance (WM) periods. During the WM, subjects were randomized into higher- and lower-satiety food groups. No differences were observed in the changes in body weight, energy intake, or eating behaviour between the groups, even despite the different macronutrient compositions of the diets. However, when regarding all study subjects, success in WM was most strongly associated with a greater increase in the flexible control of eating and experience of greater easiness of WM and control of food intake and a greater decrease in uncontrollable eating and psychological distress. Psychobehavioural factors seem to be more strongly associated with successful weight management than the predetermined satiety effect or other characteristics of the diet.
\end{abstract}

\section{Introduction}

Success in weight management is challenging. Even after successful weight loss, weight regain is very common $[1$, 2]. Therefore it is important to identify factors that are associated with and could enhance the self-regulation of food intake and other behaviours related to weight management.

Because obesity is always a result of an imbalance between the energy intake and energy expenditure, decreased energy intake is generally required for successful weight loss. Regulation of energy balance is very complex, however, with multiple mechanisms maintaining homeostasis and resisting changes in the energy balance [3]. Therefore, during negative energy balance, that is, when energy intake is lower than energy requirements, orexigenic pathways in the organism are activated [4], a usual consequence of which is a regain of reduced body weight. Successful long-term management of weight thus requires safe and effective means to counteract these compensatory regulatory mechanisms to reduce appetite and enhance satiety.

Various foods, even regardless of their energy content, may differ in their capacity to regulate satiety [5]. This can be accounted for multiple characteristics of food, such as energy density, macro- and micronutrient composition, palatability, food form, and structure [6-10]. Among different food characteristics, especially dietary fibre and protein have 
recently raised much interest as potential factors capable of increasing the satiating value of food $[11,12]$.

Indeed, higher protein intake has been shown to sustain or increase satiety both during the periods of energy restriction [13] or during the periods of isocaloric [14] or ad libitum energy intake [15]. Greater satiating effect of protein has been ascribed to greater meal-induced thermogenesis after protein-rich meals than after meals rich in carbohydrates or fat $[16,17]$. Protein also efficiently stimulates the expression of various gastrointestinal satiety hormones, and amino acids serve as precursors for specific neurotransmitters involved in appetite or are directly involved in pathways regulating food intake.

High dietary fibre intake has also been shown to contribute to increased satiety and reduced energy intake [12, 18]. Among key mechanisms, dietary fibre increases satiety and reduces energy intake by decreasing the energy density of the diet as well as by retarding nutrient absorption, gastric emptying, and intestinal passage times in the gastrointestinal tract [18]. Dietary fibre enhances satiety also through increased oral stimulation due to longer chewing time.

Several studies have shown that higher intake of dietary protein and fibre can contribute to greater weight loss or better maintenance of reduced weight $[11,12,19,20]$. Greater weight loss with high-protein or high-fibre diets has been ascribed in part to their higher satiating effects and thereby to better dietary compliance and ability to reduce spontaneous energy intake.

However, in spite of the large number of short-term studies linking various food properties to increased satiety, it is still poorly known whether the satiety value of food has an impact on the self-regulation of food intake and thereby on the regulation of body weight also at the longer term.

Different features of eating behaviour, such as restraint and disinhibition of eating, are also strong determinants of weight management [21-24]. Dietary restraint and disinhibition are psychological constructs that assess behavioural control and attitudes toward food and eating $[25,26]$. Dietary restraint refers to a tendency to consciously restrict or control food intake, whereas dietary disinhibition is a tendency to overeat in the presence of, for example, palatable foods, emotional stress, or other disinhibiting stimuli. Dietary disinhibition has been linked to higher body weight and increased risk of weight regain $[22,24]$, whereas increased dietary restraint with greater weight loss or better maintenance of reduced body weight $[23,27,28]$. Other features of eating behaviour, such as emotional eating and greater susceptibility to sensations of hunger or external food-related cues, have also been associated with greater risk of obesity and difficulties in weight management [29-32].

Therefore, the aim of the present study was to investigate factors that are associated with successful weight management in middle-aged obese men and women. We were especially interested in investigating whether foods with higher predetermined satiety values, when ingested as a part of a weight-maintenance diet, contribute to better self-regulation of food intake and reduced body weight. The study consisted thus of two distinct, consecutive phases: determination of satiating values of foods in a controlled laboratory setting
TABLE 1: Baseline characteristics of the subjects completing the study.

\begin{tabular}{lcc}
\hline & Mean \pm SD & Range (min-max) \\
\hline$n$ (males/females) & $82(21 / 61)$ & \\
Age (years) & $49.5 \pm 9.3$ & $31-63$ \\
Height $(\mathrm{cm})$ & $166.7 \pm 8.6$ & $150.0-192.0$ \\
Body weight $(\mathrm{kg})$ & $95.2 \pm 11.9$ & $71.1-122.8$ \\
Body mass index $\left(\mathrm{kg} / \mathrm{m}^{2}\right)$ & $34.2 \pm 2.5$ & $29.7-40.0$ \\
\hline
\end{tabular}

to select foods with lower and higher satiating values for the intervention and an intervention including weight-loss and weight-maintenance periods whereby the satiety-tested foods were used as a part of a weight-maintenance diet.

\section{Subjects and Methods}

2.1. Subjects in the Intervention Study. Originally 99 (28 males, 71 females) obese (inclusion criteria being body mass index (BMI) $30-40 \mathrm{~kg} / \mathrm{m}^{2}$, age $30-65$ years) subjects were recruited into the intervention study. They were recruited by an announcement in a local newspaper and among the eligible subjects who had participated previously in the studies performed at the University of Kuopio, Kuopio, Finland (currently University of Eastern Finland). The exclusion criteria of the subjects were BMI $>40$ or $<30 \mathrm{~kg} / \mathrm{m}^{2}$, pregnancy, type 1 or 2 diabetes, abnormal liver, thyroid or kidney function, polycystic ovary syndrome, less than 6 months since coronary event or operation, myocardial infarction, susceptibility to arrhythmia, diagnosed eating disorder, neuroleptic or oral cortisone medication, and excess alcohol consumption (women $>16$, men $>24$ portions/week). The subjects could not have any other diseases, medications, or life situations that would have potentially prevented them to successfully complete the study.

Altogether 82 subjects completed the whole intervention and form the study group of this study. Baseline characteristics of the completers are shown in Table 1.

The study was performed in accordance with the standards of the Helsinki Declaration. The Ethics Committee of the District Hospital Region of Northern Savo and the Kuopio University Hospital approved the study plan, and all participants gave written informed consent for their participation.

\subsection{Selection and Satiety Testing of Foods for Intervention}

2.2.1. Selection of Foods for Satiety Testing. Because the satiating value of food cannot be directly estimated based on the nutritional composition or other characteristics of foods [20,33], satiety tests were performed to identify foods with different satiety values for the intervention. Satiety tests were performed in a laboratory setting to control for potential confounders known to affect satiety measurements $[32,33]$. Satiety values were determined for food products from seven categories (yoghurt-type dairy products, crisp bread, soft bread, cheese, cold cuts, beverages, vegetable meal 
components). These food categories were selected so that the test foods would represent diversely different parts of the mixed diet. However, due to practical reasons a limited number of foods (altogether 22 foods, $2-5$ foods per food category) could be included into the satiety tests. The foods were provided by Finnish food manufacturers, and they represented both commercial products as well as products at the stage of product development.

In the selection of foods for satiety testing, the following factors were considered: the difference between foods regarding the amount of dietary fibre or protein per $700 \mathrm{~kJ}$ portion should be as large as possible, since based on literature dietary fibre and protein play an important role in the satiating effect of foods $[11,20]$. Furthermore, we chose an isocaloric portion size of $700 \mathrm{~kJ}$, which was in our previous study shown to be an energy level at which different satiety effects of test foods can be distinguished [34]. At this energy level we tried to keep portion sizes (weight or volume) as similar as possible. However, if the sizes of tested isocaloric portions differed, the volume or weight of food with potentially greater satiety value should be greater than that with potentially lower satiety value, due to possible independent effect of volume or weight on postprandial satiety [35]. Also, within each food category, the foods with potentially different satiety values should otherwise be as similar as possible.

2.2.2. Satiety Testing. The satiety values of the test foods were assessed at VTT, Espoo, Finland, before the intervention study. Altogether 35 subjects (20 males, 15 females, aged $23.3 \pm 2.2$ (range 19-28) years) recruited mainly from the Helsinki University of Technology participated in the tests. The subjects were healthy, normal-weight $(n=27)$, or at most moderately overweight $(n=8$, mean BMI $23.3 \pm 2.3$ (range 19.1-29.7) $\mathrm{kg} / \mathrm{m}^{2}$ ) due to potentially attenuated satiety responses in obese as compared with lean individuals [32]. The subjects followed normal dietary and exercise patterns and did not have any dietary restrictions or abnormal eating behaviour based on individual interviews and the Three-Factor Eating Questionnaire [25]: cognitive restraint $7.5 \pm 4.2$ (mean $\pm \mathrm{SD}$ ), disinhibition of eating $5.1 \pm 2.8$, hunger $4.9 \pm 2.5$.

Subjects participated in the satiety tests in the morning, after a minimum of 8 hours overnight fast. There was at least one day between the consecutive test sessions. Before the actual satiety tests, the subjects were familiarized with the procedure and trained to use the rating scales using typical Finnish rye bread as the practice product. The satiety tests lasted for 3 hours, during which the subjects rated their satiety-related perceptions before consuming the test product and after $20,40,60,90,120,150$, and $180 \mathrm{~min}$ from the beginning of the consumption. At each session, subjects ate the whole portion of the test food with $2 \mathrm{dL}$ of water. With crisp breads subjects consumed $50 \mathrm{~g}$ of slices of cucumber and $1.5 \mathrm{dL}$ of water. Each subject participated in the maximum 25 testing sessions, including two practice sessions.
The satiety-related sensations were evaluated using a 10 -unit scale $(0=$ not at all, $10=$ extremely $)$ before the consumption of the test product. Immediately after the consumption and during the following $180 \mathrm{~min}$, sensations were rated as a change from the starting value with a -10 $0-+10$ scale $(-10=$ a lot less than that in the beginning, $0=$ as much as that in the beginning, $+10=$ a lot more than that in the beginning) where 0 represents the baseline value [34]. A total of six satiety/hunger and thirst-related attributes were rated (hunger, thirst, desire to eat something, satiety, fullness, desire to eat the test food). The data were collected using a computerized data-collecting system (CSA, Computerized Sensory Analysis System, Compusense, Guelph, Canada, Compusense 5, version 4.6.702 SP3).

Results were analyzed as the changes in the satiety-related sensations from the baseline levels as a function of time, and the area under curve (AUC, $\mathrm{cm} \times \min$ ) was calculated. The possible area under or over the baseline level was subtracted. All curves followed the same pattern with the lowest or highest ratings $20 \mathrm{~min}$ after eating the sample, and then scores increased or decreased, respectively, during the 3hour follow-up time. Finally, 8 food pairs with significant difference in the overall $3 \mathrm{~h}$ response of the feelings of hunger or satiety were selected to be the test foods in the intervention (Table 2).

2.3. Study Protocol of the Intervention. The intervention study consisted of two periods, weight loss and weight maintenance. Subjects were informed that the aim of the study was to examine the effect of various food characteristics on the management of body weight and food intake and related mechanisms. Since satiety is a highly subjective sensation, the subjects were not told about the different satiety values of the test foods to avoid any bias due to that information.

2.3.1. Weight-Loss Period. The weight-loss period was performed by using very-low-calorie-diet (VLCD) products (Nutrifast, Leiras Finland Ltd) providing $600 \mathrm{kcal} /$ day. In addition, the subjects were allowed to consume ad libitum low-energy vegetables and noncaloric beverages. The VLCD products were given free of charge, and they were consumed for 7 weeks, followed by a 2-week transition phase during which subjects gradually finished using the VLCD products and switched back to the mixed food diet. During the weightloss period, the subjects were given dietary counselling in group sessions, 7 times during the whole period. The group sessions, lasting for 1.5 hours, were held in the evenings. Altogether $8-10$ subjects participated in each group. The same experienced nutritionist tutored all the groups. Different themes were discussed at each session (Table 3).

2.3.2. Weight-Maintenance Period. After the weight-loss period, the subjects were randomized, stratified by age and sex, into two diet groups: higher-satiety food group (HSF) and lower-satiety food group (LSF) (Table 4). The baseline characteristics of the subjects in the HSF and LSF groups are presented in Tables 4, 6, and 7 (baseline). There were 
TABLE 2: Foods selected to the intervention and their tested portion sizes, macronutrient and dietary fibre contents and $3 \mathrm{~h}$ satiety/hunger responses ( $3 \mathrm{~h}$ AUC; mean \pm standard error). Energy content of all tested food portions was $700 \mathrm{~kJ}$.

\begin{tabular}{|c|c|c|c|c|c|c|c|c|}
\hline & \multicolumn{2}{|c|}{ Dairy, yoghurt type } & \multicolumn{3}{|c|}{ Bread } & \multirow{2}{*}{$\begin{array}{c}\text { Cheese } \\
\begin{array}{c}\text { Hard cheese } \\
n=30\end{array}\end{array}$} & \multirow{2}{*}{$\begin{array}{c}\text { Cold cuts } \\
\begin{array}{c}\text { Smoked ham } \\
n=35\end{array}\end{array}$} & \multirow{2}{*}{$\begin{array}{c}\begin{array}{c}\text { Vegetable meal } \\
\text { component }\end{array} \\
\text { Vegetable patty } \\
\text { (fibre-rich) } n=35\end{array}$} \\
\hline HSF & $\begin{array}{c}\text { Pear } \\
\text { flavour } \\
n=35\end{array}$ & $\begin{array}{l}\text { Lingonberry } \\
\text { flavour }^{\mathrm{a}}\end{array}$ & $\begin{array}{c}\text { Rye crisp } \\
\text { bread } \\
n=32\end{array}$ & $\begin{array}{c}\text { Soft rye } \\
\text { bread (1) } \\
n=30\end{array}$ & $\begin{array}{c}\text { Soft rye } \\
\text { bread (2) } \\
n=29\end{array}$ & & & \\
\hline Portion size, $\mathrm{g}$ & 280 & 280 & 52 & 82 & 70 & 88 & 140 & 104 \\
\hline Protein, g & 30.6 & 30.6 & 5.6 & 5.9 & 5.6 & 29.90 & 31.6 & 9.2 \\
\hline Fat, $g$ & 0.6 & 0.6 & 1.2 & 1.1 & 1.4 & 4.4 & 4.5 & 10.7 \\
\hline Carbohydrates, g & 11.2 & 11.2 & 31.0 & 31.1 & 32.7 & 1.3 & 2.3 & 8.7 \\
\hline Dietary fibre, g & 5.6 & 5.6 & 8.9 & 9.0 & 10.5 & 0 & 0.4 & 6.9 \\
\hline Satiety, $3 \mathrm{~h}$ AUC & $464 \pm 65$ & $-^{\mathrm{a}}$ & $237 \pm 60$ & $289 \pm 56$ & $224 \pm 62$ & $103 \pm 60$ & $400 \pm 72$ & $231 \pm 53$ \\
\hline Hunger, $3 \mathrm{~h}$ AUC & $-503 \pm 67$ & $-^{\mathrm{a}}$ & $-313 \pm 67$ & $-275 \pm 54$ & $-278 \pm 75$ & $-148 \pm 61$ & $-463 \pm 86$ & $-259 \pm 59$ \\
\hline LSF & $\begin{array}{l}\text { Vanilla } \\
\text { flavour } \\
n=35\end{array}$ & $\begin{array}{c}\text { Strawberry } \\
\text { flavour } \\
n=32 \\
\end{array}$ & $\begin{array}{c}\text { Wheat } \\
\text { crisp bread } \\
n=35\end{array}$ & $\begin{array}{c}\text { Soft wheat } \\
\text { bread } \\
n=35\end{array}$ & $\begin{array}{c}\text { Thin rye } \\
\text { crisp bread } \\
n=35\end{array}$ & $\begin{array}{c}\text { Soft sliced } \\
\text { cheese } n=30\end{array}$ & $\begin{array}{c}\text { Sausage } \\
n=35\end{array}$ & $\begin{array}{l}\text { Vegetable patty } \\
\quad n=35\end{array}$ \\
\hline Portion size, $g$ & 230 & 200 & 44 & 61 & 52 & 58 & 108 & 93 \\
\hline Protein, g & 8.3 & 7.1 & 4.6 & 5.4 & 5.8 & 11.6 & 9.7 & 4.3 \\
\hline Fat, g & 4.6 & 4 & 3.5 & 2.9 & 5.8 & 12.8 & 9.7 & 11.5 \\
\hline Carbohydrates, g & 23 & 26 & 31 & 28.8 & 33 & 0.9 & 8.9 & 10.1 \\
\hline Dietary fibre, g & 0 & 0 & 2.8 & 2.0 & 9.9 & 0 & 0.3 & 3.1 \\
\hline Satiety, 3 h AUC & $111 \pm 47$ & $179 \pm 59$ & $154 \pm 50$ & $114 \pm 49$ & $122 \pm 51$ & $-2 \pm 62$ & $146 \pm 54$ & $93 \pm 62$ \\
\hline Hunger, 3 h AUC & $-173 \pm 48$ & $-148 \pm 65$ & $-186 \pm 55$ & $-130 \pm 59$ & $-161 \pm 55$ & $-1 \pm 72$ & $-171 \pm 63$ & $-124 \pm 65$ \\
\hline
\end{tabular}

HSF: higher-satiety food group; LSF: lower-satiety food group; AUC: area under the curve: positive values represent area above the baseline level, negative values represent area under the baseline level; ${ }^{a}$ a flavour variant for pear-flavoured yoghurt, not tested in the satiety tests.

TABLE 3: The themes discussed in the group sessions during the weight-loss period.

\begin{tabular}{ll}
\hline Group session & Theme \\
\hline (1) Session & $\begin{array}{l}\text { Principles of the very-low-calorie diet (VLCD, 600 kcal); tasting and choice of } \\
\text { the most pleasing options of available VLCD products for the weight-loss period } \\
\text { Energy requirement and energy consumption, physical exercise, vegetables in the } \\
\text { diet; VLCD products delivered to the subjects }\end{array}$ \\
$\begin{array}{ll}\text { (2) Session (start of VLCD) } \\
\text { (3) Session ( } 1 \text { week at VLCD) }\end{array}$ & $\begin{array}{l}\text { Thoughts and attitudes as barriers for weight management } \\
\text { (4) Session ( } 3 \text { weeks at VLCD) }\end{array}$ \\
(5) Session ( 5 weeks at VLCD) & Good and bad dietary fats, package labelling \\
(6) Session (7 weeks at VLCD; start of transition phase) & Transition phase diet (800 kcal), control of food intake \\
(7) Session (start of weight-maintenance period) & Principles of the weight-maintenance diet and the use of test foods
\end{tabular}

no significant differences at the baseline between the groups except for external eating, which was greater in the HSF than in the LSF group $(P=0.02)$, and the proportion of daily energy from carbohydrates, which was greater in the LSF than in the HSF group $(P=0.03)$. However, the total carbohydrate intake was the same in both groups.

Neither of the diets was considered a control diet. During the 24-week weight-maintenance period, subjects were instructed to maintain their weight loss but not to continue actively losing weight. The subjects in the HSF consumed the test foods with higher satiety value the subjects in the LSF consumed the test foods with lower satiety value as a part of their weight-management diet. The way of using the test foods and all dietary counselling was otherwise the same in both groups.

The test foods aimed to cover about $30 \%$ of the individually estimated daily energy requirements. The proportion of test foods was tested in the pilot study performed prior to the intervention study to find out what was the highest realistic amount of the test foods that could be consumed as a part of the diet. 19 subjects ( 5 men, 14 women) of same age $(51.2 \pm 10.0$ years $)$ and BMI $\left(31.3 \pm 4.4 \mathrm{~kg} / \mathrm{m}^{2}\right)$ as the subjects in the intervention study participated in the pilot and used the test foods for two weeks as a part of their 
habitual diet. At the end of this period, they were interviewed about their experiences, and the intervention protocol was further modified using this information.

The individual energy requirements were estimated by calculating the basal metabolic rate by the formula of Mifflin St-Jeor [36]. To take into account the likely reduction of the energy expenditure due to the recent marked weight loss [37], the resultant values were deducted by $5 \%$. The results were then multiplied by factor 1.3 to take into account the energy requirements due to any physical activity. Based on the experiences from the pilot study, the resultant values were then deducted by the value $333.45 \mathrm{kcal}$ to take into account the difference between the calculated energy requirements and the reported energy intakes. Thus the final equations for the calculation of the energy requirements were [ $(9.99 *$ weight $(\mathrm{kg})+6.25 *$ height $(\mathrm{cm})-4.92 *$ age $(\mathrm{yrs})+5) *$ $0.95 * 1.3]-335.45 \mathrm{kcal}$ for men and [ $89.99 *$ weight $(\mathrm{kg})$ $+6.25 *$ height $(\mathrm{cm})-4.92 *$ age $(\mathrm{yrs})-161) * 0.95 * 1.3$ ] - $335.45 \mathrm{kcal}$ for women. The resultant individual energy levels were rounded up to the nearest $100 \mathrm{kcal}$ and varied from $1200 \mathrm{kcal}$ to $2300 \mathrm{kcal} /$ day. The amounts of portions of different test foods used per day were calculated and advised based on these energy levels.

The subjects received the test foods free of charge from the University of Kuopio (current the University of Eastern Finland) every two weeks. The test foods were given as the blank packages so that the subjects could not identify their exact content on the basis of, for example, comparable commercial products. During every visit, the subjects' body weight was measured, and they were given written instructions about the use of the test foods as well as the weight-management diet in general.

The written instructions included the numbers of the portions of each test food and the recommendations of the number of servings within each food group (vegetables/ berries/fruit, dairy, potatoes and cereals, meat/fish/poultry, fat) to be consumed each day so that the total energy intake would cover the individually estimated daily energy requirement. The subjects were, however, informed that the diet was otherwise freely selected. In addition, to allow the possible satiety effect of test foods to function, subjects were told that they could increase or decrease the number of food servings (other than test foods) if still hungry or if sated, respectively.

Table 5 shows the portion sizes and typical numbers of daily portions of each test food as instructed to be consumed during the intervention. The portion sizes could be different from those used in the standard satiety tests because the foods were used as a part of a diet and were therefore targeted to represent typical portion sizes of each food. The number of the portions/day varied among different energy levels and from day to day. In addition, in order to reduce the risk of monotony and boredom due to the continued and frequent use of a quite limited number of test products, test foods within each list varied so that each two weeks list included 6 out of 8 test foods. On each week, the subjects were allowed to have one day free of the use of the test foods, if they wished. The subjects recorded the use of the test foods for the whole duration of the weight-maintenance period. These

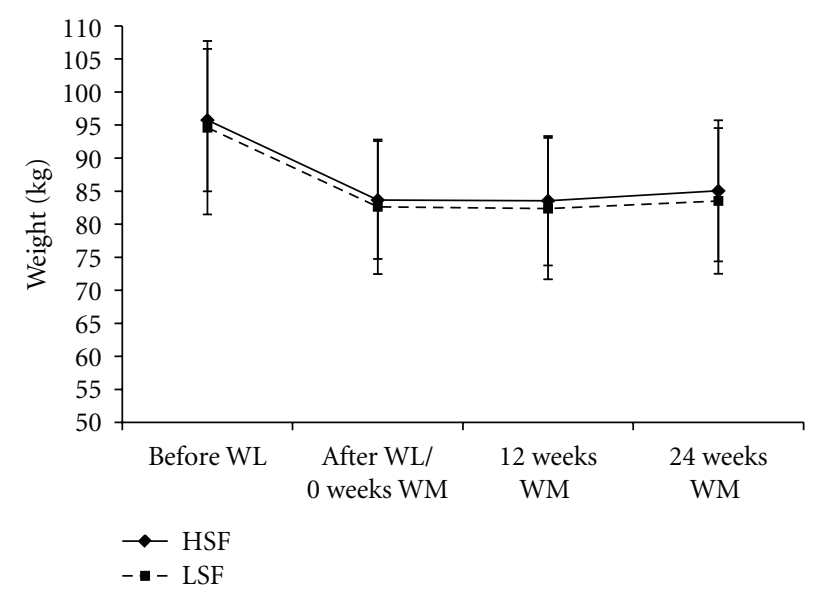

Figure 1: Changes in the body weight during the study. No significant differences between the groups. HSF: higher-satiety food group $(n=42)$; LSF: lower-satiety food group $(n=40)$; WL: weight loss; WM: weight maintenance.

recordings were used when calculating the compliance (i.e., the use of the test foods as compared with the instructed use).

The subjects were not given any specific instructions about physical activity but were advised to keep it at their habitual level.

\subsection{Measurements in the Intervention}

2.4.1. Anthropometric Measurements. Body weight was measured in the morning after 12 hours fast after voiding in the normal indoor clothing using a digital scale (Vogel \& Halke, Hamburg, Germany) with the weighing accuracy of $0.1 \mathrm{~kg}$. The measurements were done at the separate study visits in the beginning of the weight-loss period before any weight loss had occurred, at the end of the weightloss period (i.e., the beginning of the weight-maintenance period), and at 12 and 24 weeks after the beginning of the weight-maintenance period (Figure 1). Height was measured using a wall-mounted stadiometer to the nearest $0.1 \mathrm{~cm}$ in the beginning of the weight-loss period. Body mass index (BMI) was calculated (weight $(\mathrm{kg}) /$ height $\left.(\mathrm{m})^{2}\right)$.

2.4.2. Dietary Intake. Subjects completed 4-day food records altogether five times during the study: before the weightloss period and at $6,12,18$, and 24 weeks from the beginning of the weight-maintenance period. The portion sizes were estimated using household measures. Nutrient intake was calculated with Diet32 analysis program (Aivo Finland Oy) using the Finnish Food Composition Database, Fineli (National Institute for Health and Welfare).

2.4.3. Eating Behaviour and Psychological Distress. Various features of eating behaviour were evaluated by standardized and validated self-report questionnaires. Three-Factor Eating Questionnaire (TFEQ) was used to measure cognitive restraint of eating and divided also to the flexible and rigid parts of the restraint [38], disinhibition of eating, and 
TABLE 4: Subjects in the higher-satiety food (HSF) and lower-satiety food (LSF) groups. Mean \pm SD.

\begin{tabular}{lccc}
\hline & HSF & LSF & $P^{\mathrm{a}}$ \\
\hline$n$ (males/females) & $42(12 / 30)$ & $40(9 / 31)$ & $49.1 \pm 9.1$ \\
Age (years) & $49.6 \pm 9.5$ & $165.8 \pm 9.3$ & $0.53^{\mathrm{b}}$ \\
Height $(\mathrm{cm})$ & $167.6 \pm 8.0$ & $94.6 \pm 13.1$ & 0.35 \\
Body weight $(\mathrm{kg})$, before weight loss & $95.7 \pm 10.8$ & $82.6 \pm 10.2$ & 0.67 \\
Body weight $(\mathrm{kg})$, after weight loss & $83.7 \pm 8.9$ & $34.3 \pm 2.7$ & 0.63 \\
Body mass index $\left(\mathrm{kg} / \mathrm{m}^{2}\right)$, before weight loss & $34.0 \pm 2.3$ & $30.0 \pm 2.3$ & 0.60 \\
Body mass index $\left(\mathrm{kg} / \mathrm{m}^{2}\right)$, after weight loss & $29.8 \pm 2.1$ & & 0.63 \\
\hline
\end{tabular}

${ }^{\mathrm{a}}$ Student's $t$-test; ${ }^{\mathrm{b}}$ Chi-square.

TABLE 5: Instructed portion sizes, possible numbers of daily portions, and their energy and macronutrient contents per portion during the intervention.

\begin{tabular}{|c|c|c|c|c|c|c|c|}
\hline & $\begin{array}{l}\text { Portion } \\
\text { size, } g\end{array}$ & $\begin{array}{c}\text { Number of } \\
\text { portions/day }\end{array}$ & $\begin{array}{c}\text { Energy, } \\
\text { kcal }\end{array}$ & Protein, $g$ & Fat, $g$ & Carbohydrates, g & Dietary fibre, $g$ \\
\hline \multicolumn{8}{|c|}{ HSF } \\
\hline Yoghurt (pear flavour) & 150 & $1-2$ & 90 & 16.5 & 0.3 & 6.0 & 3 \\
\hline Yoghurt (lingonberry flavour) & 150 & $1-2$ & 90 & 16.5 & 0.3 & 6.0 & 3 \\
\hline Rye crisp bread & 12.9 & $1-3$ & 41 & 1.4 & 0.3 & 7.7 & 2.2 \\
\hline Soft rye bread (1) & 43 & $1-3$ & 86 & 3.1 & 0.6 & 16.3 & 4.7 \\
\hline Soft rye bread (2) & 30 & $1-3$ & 75 & 2.4 & 0.6 & 14.0 & 4.5 \\
\hline Hard cheese & 125 & $0.25-0.75$ & 238 & 42.5 & 6.3 & 1.9 & 0 \\
\hline Smoked ham & 6.2 & 4-10 & 7.5 & 1.4 & 0.2 & 0.1 & 0.2 \\
\hline Vegetable patty (fibre-rich) & 60 & $1-2$ & 96 & 5.3 & 6.2 & 5.0 & 4.0 \\
\hline \multicolumn{8}{|c|}{ LSF } \\
\hline Yoghurt (vanilla flavour) & 130 & $1-2$ & 91 & 4.7 & 2.6 & 13.0 & 0 \\
\hline Yoghurt (strawberry flavour) & 110 & $1-2$ & 91 & 3.9 & 2.2 & 14.3 & 0 \\
\hline Wheat crisp bread & 12.5 & $1-2$ & 50 & 1.3 & 1.0 & 8.8 & 0.8 \\
\hline Soft white wheat toast bread & 25 & $1-4$ & 70 & 2.2 & 1.2 & 11.8 & 0.8 \\
\hline Thin rye crisp bread & 6.3 & $2-10$ & 20 & 0.7 & 0.7 & 4.0 & 1.2 \\
\hline Soft sliced cheese & 19 & $1-3$ & 55 & 3.8 & 4.2 & 0.3 & 0 \\
\hline Sausage cold cut & 13.4 & $1-5$ & 20 & 1.2 & 1.2 & 1.1 & 0.4 \\
\hline Vegetable patty & 60 & $1-2$ & 10.5 & 2.8 & 7.4 & 6.5 & 2.0 \\
\hline
\end{tabular}

HSF: higher-satiety food group, LSF: lower-satiety food group; ${ }^{\text {a }}$ range, the number of the portions varied from day to day and among different energy levels.

susceptibility to hunger [25]. The Dutch Eating Behaviour Questionnaire (DEBQ) was used to measure restraint of eating, emotional eating, and external eating [39]. Binge Eating Scale (BES) assessed the presence of binge eating [40]. The subjects filled in the questionnaires in the beginning of the weight-loss period and after 12 and 24 weeks of weight maintenance.

Psychological distress was evaluated by the General Health Questionnaire [41] in the beginning and at the end of the weight-loss period as well as after 12 and 24 weeks of weight maintenance.

During the weight-maintenance period, the subjects evaluated at the end of each week their overall well-being, bowel function, hunger, satiety, and easiness of control of food intake by the 9-point scale $(1=$ not at all/extremely bad, ..., $9=$ a lot/extremely good). In addition, at the end of each dietary data collection day, the subjects rated how difficult/easy they had experienced control of food intake that day by using 7 -point scale $(1=$ very difficult, $\ldots, 7=$ very easy).

At the end of the study, the subjects filled in a final questionnaire to assess how they had experienced the weightmaintenance period in general $(1=$ very difficult, $\ldots, 10=$ very easy) and what they had liked about the test foods $(1=$ did not like at all, .., 9 = liked very much).

2.5. Statistical Analyses. The statistical analyses were performed with SPSS for Windows software (SPSS for windows, version 14.0, USA). The results are expressed as mean and standard deviation (SD) with a value $P<0.05$ as a criterion for the statistical significance, unless not otherwise specified.

In the satiety tests, paired samples $t$-test was used to evaluate the differences between the food pairs within each food category.

In the intervention study, independent samples $t$-test (Student's $t$-test) and Chi-square test were used to compare 
the baseline values between the study groups. Linear mixedeffect modelling was used to compare the effect of the study group on the changes in the examined variables. The associations between the variables in the whole study population were analyzed by Spearman's correlation test and by partial correlation adjusted by the study group.

\section{Results}

3.1. Adherence and Compliance. Altogether 82 out of 99 subjects completed the intervention. There were 17 subjects who dropped out, three subjects ( 2 men, 1 woman) during the weight-loss period and 14 subjects ( 6 men, 9 women) during the weight-maintenance period. There were no differences in the dropouts during the weight-maintenance period between the HSF ( 8 ( 3 men, 5 women)) and the LSF groups (6 (2 men, 4 women)).

The use of test foods, as an indicator of compliance, was equal in both groups (\% of the instructed use, calculated from the individual recordings during the weightmaintenance period: $100.8 \pm 9.0 \%$ versus $99.1 \pm 9.1 \%$, HSF versus LSF), as well as the proportion of energy ingested from the test foods (mean during the weight-maintenance period: $30.7 \pm 6.1 \%$ versus $29.0 \pm 5.0 \%$, HSF versus LSF). The subjects in the HSF group generally liked the test foods they used more than in the subjects in the LSF group $(7.1 \pm 1.0$ versus $6.4 \pm 1.0, P=0.003$ ).

\subsection{Main Effects}

3.2.1. Body Weight. Weight changes were comparable between the HSF and the LSF groups (Figure 1). The weight reduced by about $12 \mathrm{~kg}$ during the weight-loss period in both groups (HSF $-12.5 \pm 2.4 \%$, LSF $-12.4 \pm 2.6 \%$ of the body weight at the baseline). During the weightmaintenance period, there was only a very slight regain in the mean body weight with no significant difference between the groups (HSF $1.3 \pm 3.5 \%$, LSF $0.9 \pm 3.5 \%$ ). The interindividual variation in the success to maintain the reduced body weight during the weight-maintenance period was large, with weight changes varying from $8.8 \%$ further weight reduction to $9.8 \%$ weight regain.

3.2.2. Dietary Factors. The overall energy intake was similar in both groups with no significant differences in overall energy intake during the intervention (Table 6). Only at the end of the study, the energy intake changed differently in the HSF and LSF groups, with continuing gradual increase in the energy intake in the HSF group and a small decrease in the LSF group $(P=0.02)$. Instead, the macronutrient composition of the diet changed differently in the HSF and the LSF groups. The intakes of dietary protein and fibre increased at the beginning of the weight-maintenance period in the HSF group whereas they remained about the same in the LSF group ( $P<0.001$ for all). The intakes of dietary fiber and protein were thus higher in the HSF than those in the LSF group for the whole duration of the weight-maintenance period $(P<0.001$ for all). The intake of dietary fat decreased from the beginning of the study to the weight-maintenance period in both groups, the decrease being greater and thus overall fat intake lower in the HSF than in the LSF group during the weight-maintenance period $(P<0.001)$. The total carbohydrate intake decreased from the beginning of the study to the weight maintenance in both groups. The reduction was greater in the HSF group than that in the LSF group $(P=0.04)$. As the percentage of energy, carbohydrate intake remained about the same during the whole study being greater in the LSF group $(P<0.001)$. The alcohol intake decreased from the beginning of the study in both groups, being, as the percentage of energy, somewhat greater in the HSF group than that in the LSF group $(P=0.04)$.

The observed differences in dietary protein, fibre, fat, and carbohydrate intakes during the weight-maintenance period were due to the different macronutrient contents of the test foods (Table 5). The composition and energy intake of the freely selected part of the diet was the same in both groups (data not shown).

3.2.3. Psychobehavioural Factors. The subjects in the HSF and the LSF groups experienced the study very similarly based on their responses in the final questionnaire at the end of the study (estimated easiness of the weight maintenance period: HSF $7.1 \pm 1.8$, LSF $7.1 \pm 1.9$ ). Neither did they report any differences in the easiness of the control of food intake or other conditions that were evaluated along the study (overall wellbeing, bowel function, hunger, satiety).

Cognitive restraint of eating, both flexible and rigid, increased in both the HSF and the LSF groups after the weight-loss period, as measured by the TFEQ and the DEBQ questionnaires (Table 7). At the same time, disinhibition of eating, susceptibility to hunger, and binge eating as well as emotional and external eating decreased in both groups. There were no significant differences in the changes between the groups, except in the external eating which decreased more in the HSF group than those in the LSF group $(P=0.007)$ most likely due to higher scores in the HSF at the beginning of the study. Neither were there any significant differences between the groups in the changes in the psychological distress, as assessed by GHQ, which alleviated in both groups after the weight loss then gradually returning towards the baseline level.

3.2.4. Predictors of Weight Maintenance. Due to great interindividual variation in the success to maintain reduced body weight, irrespective of the study group, the predictors of weight maintenance were analysed in the whole study population. The changes in the eating behaviour during the study were significantly associated with the weight maintenance (Table 8). The success in weight maintenance was associated with the greater increase in the cognitive restraint of eating, especially in the flexible control of eating as well as the greater decrease in the disinhibition of eating, susceptibility to hunger, binge eating behaviour, external eating, and psychological distress. Most of these changes, that is, increase in the flexible control of eating and the decrease in susceptibility to hunger, binge eating behaviour, 
external eating, and psychological distress, were associated with better weight maintenance also after adjusting for group membership during the weight-maintenance period (Table 8).

The self-reported easiness of the weight-maintenance period resulted to be a single factor which was most strongly associated with the successful maintenance of reduced body weight during the weight-maintenance period $(r=-0.47$, $P<0.001, n=82$ ). The association was significant, even slightly stronger, also after making adjustment for study group (partial correlation $r=-0.52, P<0.001$ ). Those subjects who experienced the weight-maintenance period the easiest also managed better than those experiencing it more difficult. Similarly, the self-reported easiness of the control of food intake, as assessed at the different phases of the weightmaintenance period, correlated significantly with the weight maintenance (mean of weekly assessments, $r=-0.39, P<$ $0.001, n=82$ ), also after adjusting for group membership (partial correlation $r=-0.39, P<0.001$ ). The easier the subjective control of food intake, the more successful the weight maintenance.

Among the dietary determinants of successful weight maintenance, the compliance (i.e., the use of the test foods) correlated with the final outcome; the higher the compliance, the better the reduced body weight maintained during the weight-maintenance period $(r=-0.27, P=0.02, n=$ 82). This association was seen also after adjusting for the study group (partial correlation $r=-0.23, P=0.05$ ). Lower energy intake according to the food diaries during the weight-maintenance period was also associated with the better maintenance of reduced body weight $(r=0.24, P=$ $0.03, n=82$ ) also when adjusted by group membership (partial correlation $r=0.22, P=0.047$ ).

\section{Discussion}

This study investigated dietary and psychobehavioural factors associated with the success in weight maintenance. More specifically, we were interested in whether foods with predetermined satiety values consumed in free-living conditions as a part of a weight-maintenance diet would affect self-regulation of food intake and thereby weight management. To our knowledge, no previous studies have been published on the issue. In contrast to expectation, the diet containing foods with higher predetermined satiety value did not contribute to better weight management. This was even despite the obvious differences in the macronutrient contents of the diets, especially the differences in the amounts of dietary protein and fibre, which by themselves could also have been expected to influence satiety or weight management $[11,12]$.

Nevertheless, the present results were interestingly in line with the findings of a recent large intervention comparing the effects of weight-loss diets differing in the proportions of dietary fat, protein, or carbohydrate [42]. In that study, no diet was superior in reducing body weight. There were also no significant differences in satiety, hunger, or diet satisfaction among the diets. Instead, the strongest determinant of successful weight loss was an attendance at the group sessions, suggesting that behavioural factors rather than the composition of the diet are more important for the success of weight loss. Also in the present study the successful maintenance of reduced weight was not primarily associated with the diet-related factor, but rather with the psychobehavioural variables related especially to eating behaviour. Also participants' subjective experiences about the easiness of the intervention and control of food intake were associated with better weight maintenance. The only diet-related factors that were significantly associated with the weight management were lower energy intake and better compliance of the use of the test products, which, on the other hand, could be seen also as behavioural factors similarly as the attendance at group sessions in the Sacks et al.'s [42] study. Thus, as Sacks et al. [42] also pointed out, behavioural and psychological factors rather than macronutrient metabolism seem to have the main influence on the success of longer-term weight management.

Changes in various features of eating behaviour were associated with the better success in weight management. All the observed changes, that is, increase in the cognitive restraint of eating and decrease in binge eating, external eating, disinhibition of eating, and susceptibility to hunger, were into the direction that could be suggested to represent better self-control of eating. These changes were also well in line with several previous findings, thus further confirming the important role of eating behaviour in the successful weight management $[27,28,30,31,43]$. When distinguishing cognitive restraint of eating into flexible and rigid forms of restraint behaviour [38], it was specifically the flexible restraint that was associated with the better maintenance of reduced weight. This is in accordance with the earlier findings $[22,27,31,38,44]$ and also with the concept of flexible restraint. By definition, flexible restraint of eating is a form of eating behaviour characterized by a more graduated approach to eating, dieting, and weight in contrast to rigid control which is characterized by a dichotomous, all-or-nothing approach to eating, dieting, and weight [38]. A form of restrained eating in which flexible approach is adopted seems thus to be beneficial to effective weight control $[31,45]$. The beneficial effect of flexible control of eating on weight management has been documented earlier both in cross-sectional and in prospective analysis. In crosssectional settings, flexible restraint has been shown to predict lower fatness and BMI $[22,46]$. In prospective studies, successful weight change has been more strongly associated with flexible than with rigid form of cognitive restraint of eating [31, 38, 46, 47]. Thus, as Teixeira et al. [31] concluded, sustained weight loss seems to require that subjects adopt a flexible eating self-regulation pattern that allows them to modify their eating behaviour and quite likely also their physical activity by appropriate ways in this complex food environment. Successful restraint of eating can also be linked with higher self-control capacity in general [45]. Therefore attempts to enhance self-regulation could be of value to those attempting to control body weight and food intake. 


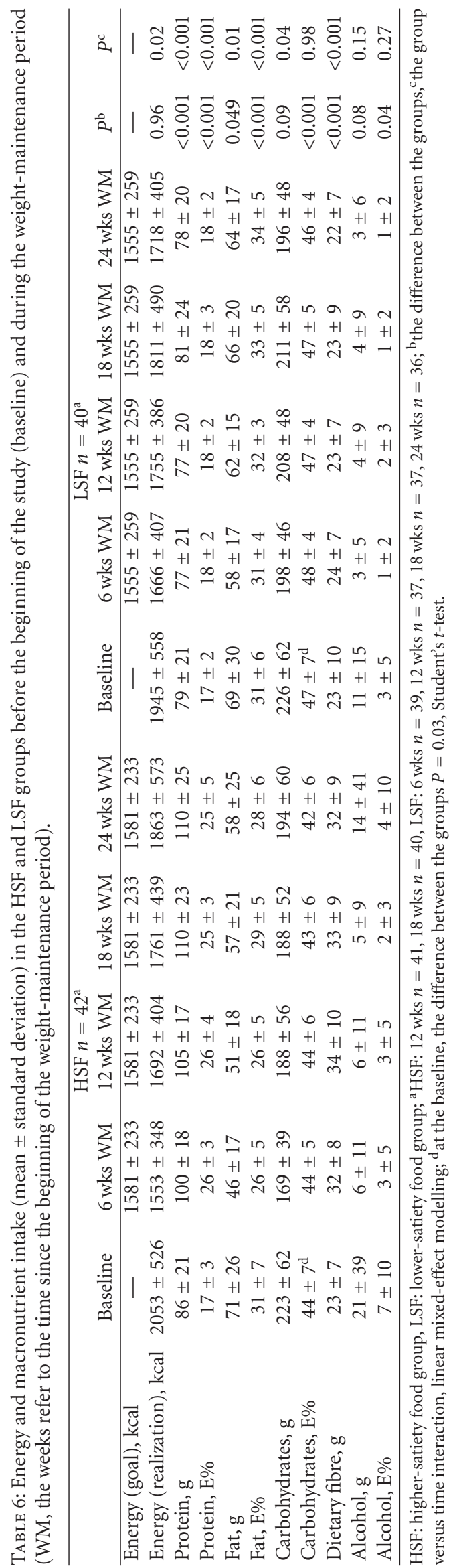




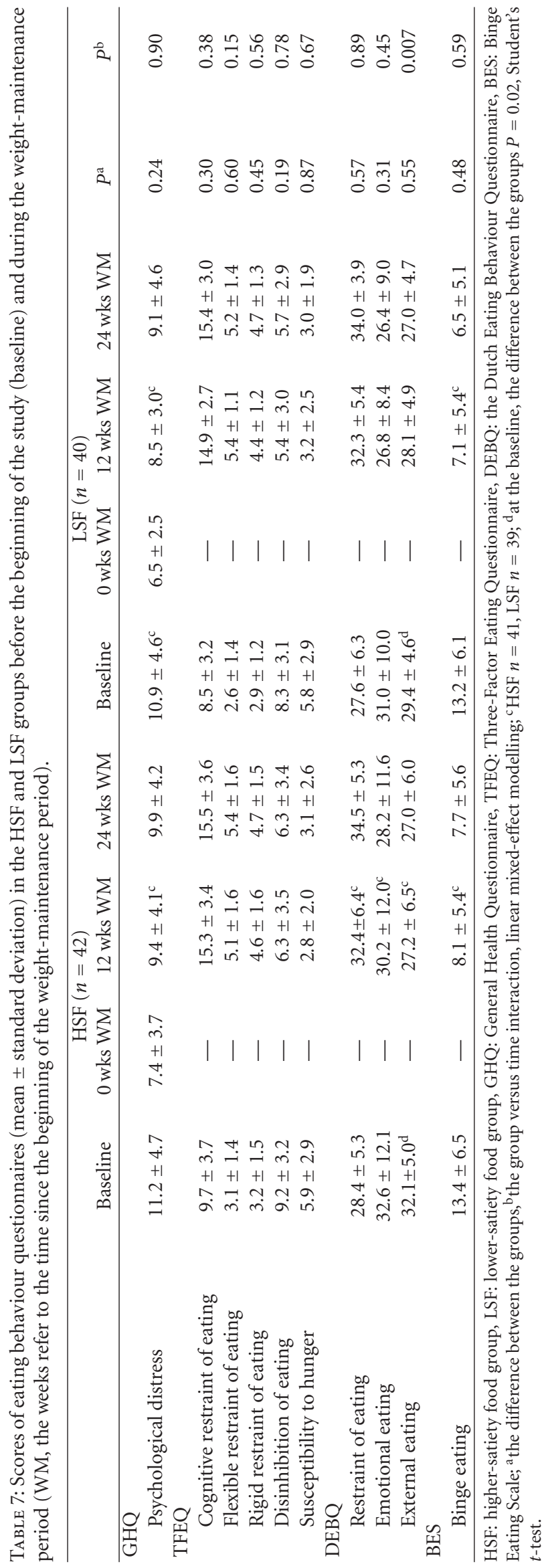


TABLE 8: Spearman and partial correlation coefficients between the changes in eating behaviour and psychological distress from the beginning of the study to the end of the weight-maintenance period and changes (\%) in body weight during the weight-maintenance period $(n=82)$.

\begin{tabular}{|c|c|c|c|c|}
\hline Change in & $r^{\mathrm{a}}$ & $P$ & $r^{\mathrm{b}}$ & $P$ \\
\hline \multicolumn{5}{|l|}{ Three-Factor Eating Questionnaire } \\
\hline (i) Cognitive restraint of eating & -0.23 & 0.04 & -0.21 & 0.07 \\
\hline (ii) Flexible restraint of eating & -0.33 & 0.002 & -0.31 & 0.006 \\
\hline (iii) Rigid restraint of eating & -0.003 & 0.98 & -0.01 & 0.90 \\
\hline (iv) Disinhibition of eating & 0.22 & 0.048 & 0.18 & 0.12 \\
\hline (v) Susceptibility to hunger & 0.28 & 0.01 & 0.31 & 0.005 \\
\hline \multicolumn{5}{|l|}{ Dutch Eating Behaviour Questionnaire } \\
\hline (i) Restraint of eating & -0.06 & 0.63 & -0.06 & 0.59 \\
\hline (ii) Emotional eating & 0.11 & 0.35 & 0.05 & 0.66 \\
\hline (iii) External eating & 0.25 & 0.02 & 0.25 & 0.02 \\
\hline \multicolumn{5}{|l|}{ Binge Eating Scale } \\
\hline (i) Binge eating & 0.26 & 0.02 & 0.24 & 0.03 \\
\hline \multicolumn{5}{|l|}{ General Health Questionnaire } \\
\hline (i) Psychological distress & 0.24 & 0.03 & 0.23 & 0.04 \\
\hline
\end{tabular}

${ }^{\mathrm{a}}$ Spearman's correlation; ${ }^{\mathrm{b}}$ partial correlation, adjusted by study group.

Also recent brain imaging studies have confirmed links between body weight, restraint, and self-regulation. Individuals with high dietary restraint showed increased neural activity in the cortical and subcortical control and reward areas, especially at the dorsal prefrontal cortex and dorsal striatum, in response to meal ingestion [48] or pictures of palatable foods [49]. This suggests that the cognitive control of food intake is achieved by modulating neural circuits controlling inappropriate behavioural responses and food reward $[48,49]$. This may also be the way to counterbalance the physiological compensatory changes, like reductions in energy expenditure and circulating mediators of appetite, which do promote weight regain after weight loss [4].

As a concept, self-control is close to the concept of self-efficacy which refers to an individual's belief that she or he can successfully execute a sequence of actions in a specified context [50]. Self-efficacy has been shown to be an important predictor of successful weight management $[31,51,52]$. Self-efficacy was, unfortunately, not measured in the present study. However, interestingly, the experience of greater easiness of weight maintenance as well as easiness of control of food intake was associated with the more successful maintenance of reduced body weight. This suggests that those experiencing intervention easier might also have felt themselves more competent and efficient in managing their attempts to maintain reduced body weight. As further support for this, greater improvement in psychological distress was also associated with better weight management. However, it should be noticed that the ratings of easiness of weight management or control of food intake are highly subjective measures and strongly susceptible to reverse causality or confounding. They could thus also be simply consequences of changes in other psychobehavioural variables or influenced by the body weight change itself. Nevertheless, tools and approaches which could enhance subjective experience of self-control and thereby likely also the experienced easiness of weight management should thus be taken into account to increase the long-term success of weight management. In current behavioural interventions, still fairly little attention has been devoted to, for example, psychological resources needed for the long-term management of body weight or other health-related lifestyle habits [53].

In the present study, except for the lower energy intake and better compliance of the use of the test foods, other dietary factors were not associated with better weight management. This was despite the fact that the differences in the protein and fibre contents of the study diets were comparable with those reported in previous studies yet demonstrating better weight management on the diets with higher protein $[14,54-56]$ or fibre content $[12,18]$. Indeed, in a recent Diogenes study even smaller difference $(4.5-6.5 \%$ versus $7.5 \%$, Diogenes versus present study) in the dietary protein intake between the study groups was followed by significant, although relatively small $(0.9 \mathrm{~kg})$, difference in body weight regain after a successful weight loss [56]. No differences were, however, detected in satiety even in that study. The authors ascribed this to be due to too subtle satiety effects of the diets to be subjectively measured.

On the other hand, the positive association between protein intake and satiety has been suggested to be evident only when protein intake is greater than protein requirements $[16,57]$. Thus the degree of satiation may be influenced by the absolute amount of protein. Indeed, Lejeune et al. [57] reported that the greater satiating effect of dietary protein was seen only when protein intake was as much as $2.6 \mathrm{~g} / \mathrm{kg}$. This is much more than what was the protein intake $(1.3 \mathrm{~g} / \mathrm{kg})$ in the HSF group in the present study. It could therefore be argued that the protein intake was not enough to contribute to possible significant effect on long-term 
satiety. However, much higher protein intake would have been impractical to achieve and would not have represented a normal balanced diet.

Howarth et al. [18] estimated that about $14 \mathrm{~g}$ increase in daily dietary fibre intake in ad libitum conditions was associated with about $10 \%$ decrease in dietary energy intake and consequent decrease in body weight. In the present study the HSF group increased their daily dietary fibre intake approximately by $10 \mathrm{~g}$. It could therefore be argued that the dietary fibre content of the study diet was still not enough to contribute to more successful weight management, although already smaller amounts of dietary fibre have been demonstrated to be effective [12].

When interpreting the results, it should be noticed that the weight-maintenance diet was not totally ad libitum since the participants were given instructions about the recommended number of portions to be consumed within each food group. This could naturally have diminished the possible influence of dietary fibre and protein and their potential satiety effect on the self-regulation of food intake and thereby on the maintenance of reduced body weight. In line, most studies reporting greater weight loss after highprotein than low-protein diet have been those allowing ad libitum food intake, whereas only few of the studies that have provided isocaloric high- versus low-protein diets have shown significant weight loss results [14, 19, 32]. We cannot rule out that if the proportion of foods with different satiety values would have been greater than $30 \%$ of energy intake, a possible satiety effect could have been seen. This was, however, the highest amount of test foods that could be realistically included into the diet without an excessive risk of dietary noncompliance due to the continuous use of only limited number of test foods. On the other hand, the proportion of test foods should not be too high to limit freedom in the remaining diet to show potential differences in energy intake. Finally, all the other dietary counselling given to the subjects during the study, especially in the group sessions before the weight-maintenance period, might also have diminished the possible differences between the groups.

Another central methodological issue is that, to our knowledge, this was the first time to examine whether foods with predetermined satiety values could contribute to weight management. Thus, at the same time, the study examined the predictive value of a single satiety measurement of food on satiety during continued use in a free-living context. As the results suggest, the different predetermined satiety values of the test foods did not influence weight management in a freeliving situation. No differences were seen either in energy intake or in the weekly ratings of hunger or satiety. Even the experienced easiness of weight management was virtually identical between the study groups. This confirms how much more difficult it is to get reliable data about satiety outside a controlled laboratory setting. It also raises issues as to how far laboratory data can really be extrapolated to free-living conditions [32]. Yet controlled laboratory testing is a general and recommended practice when assessing the satiety values of foods [33].

Naturally, the laboratory testing conditions are also of importance. In the present study, the satiety values of the test foods were determined in a separate group representing mostly relatively young, normal-weight subjects. The demographic characteristics of the subjects in the satiety tests and in the intervention were thus quite different. Normalweight and overweight subjects were, however, selected for satiety testing instead of obese individuals due to potentially attenuated satiety responses in obese as compared with lean individuals [32], to be able to demonstrate actual differences in satiety values between the test products. Furthermore, in the satiety tests, the foods were tested as isocaloric portions, and, during the intervention, the recommended portion sizes were adjusted to represent typical portion sizes of each food relative to everyday food consumption. The test foods also varied in some other dimensions, such as macronutrient content and palatability. All this could have affected the behaviours observed over the weight-maintenance period and perhaps obscured the potential effect of satiety value of foods. Nevertheless, although satiety value of foods should ideally be tested in subjects and conditions representing the target situation as close as possible, controlling all the prevailing conditions comparable to free-living conditions may be unrealistic. Furthermore, most of the foods are rarely eaten as such but usually as a part of a mixed meal or a snack. Thus, the satiety values do vary also according to other prevailing, mostly uncontrollable circumstance-related factors.

It could be argued that factors that predict subsequent weight maintenance are not necessarily the same if weight loss is initially achieved rapidly with a VLCD compared with methods inducing more gradual weight loss. A recent study comparing factors associated with successful weight maintenance in relation to initial method of weight loss (i.e., VLCD versus commercial program or self-guided approach) did not, however, observe any differences across the methods on the changes in eating behaviour or dietary intake [58], which further supports the relevance of the present findings on the success of weight management.

\section{Conclusions}

Foods with higher predetermined satiety value, when ingested as a part of a controlled weight-maintenance diet, did not contribute to better weight maintenance. Instead, success in weight maintenance was associated with a greater increase in flexible control of eating and greater decrease in uncontrollable eating and psychological distress. Thus, means to support changes in these psychobehavioural factors are of essential importance in successful long-term weight management.

\section{Acknowledgments}

The authors gratefully acknowledge Eeva Lajunen for her excellent laboratory assistance and authorized nutritionists M.S. Anne Jääskeläinen, M.S. Tarja Martikainen, M.S. Reetta Mustonen, and M.S. Taisa Venäläinen for their excellent assistance in nutritional and other practical duties throughout the intervention study. The skillful assistance 
of technicians Pirkko Nousiainen, Heidi Eriksson, and Ulla Österlund and M.S. Nora Ohls in conducting the satiety tests at VTT is also greatly appreciated. This work was supported by the Finnish Funding Agency for Technology and Innovation (Tekes, grant 40100/07) and Finnish food manufacturers (Atria Plc, Fazer Group Ltd, Arla Ingman Ltd, Valio Ltd, Sinebrychoff Ltd, Vaasan Ltd, Foodfiles Ltd, Leiras Finland Ltd) and partly by the SalWe Research Program for Mind and Body (Tekes grant 1104/10).

\section{References}

[1] J. Ikeda, N. K. Amy, P. Ernsberger et al., "The national weight control registry: a critique," Journal of Nutrition Education and Behavior, vol. 37, no. 4, pp. 203-205, 2005.

[2] V. Hainer, H. Toplak, and A. Mitrakou, "Treatment modalities of obesity: what fits whom?” Diabetes Care, vol. 31, supplement 2, pp. S269-S277, 2008.

[3] P. J. Havel, "Peripheral signals conveying metabolic information to the brain: short-term and long-term regulation of food intake and energy homeostasis," Experimental Biology and Medicine, vol. 226, no. 11, pp. 963-977, 2001.

[4] P. Sumithran, L. A. Prendergast, E. Delbridge et al., "Longterm persistence of hormonal adaptations to weight loss," New England Journal of Medicine, vol. 365, no. 17, pp. 1597-1604, 2011.

[5] S. H. A. Holt, J. C. Brand Miller, P. Petocz, and E. Farmakalidis, "A satiety index of common foods," European Journal of Clinical Nutrition, vol. 49, no. 9, pp. 675-690, 1995.

[6] C. Marmonier, D. Chapelot, and J. Louis-Sylvestre, "Effects of macronutrient content and energy density of snacks consumed in a satiety state on the onset of the next meal," Appetite, vol. 34, no. 2, pp. 161-168, 2000.

[7] M. Yao and S. B. Roberts, "Dietary energy density and weight regulation,” Nutrition Reviews, vol. 59, no. 8, pp. 247-258, 2001.

[8] L. B. Sørensen, P. Møller, A. Flint, M. Martens, and A. Raben, "Effect of sensory perception of foods on appetite and food intake: a review of studies on humans," International Journal of Obesity, vol. 27, no. 10, pp. 1152-1166, 2003.

[9] D. E. Gerstein, G. Woodward-Lopez, A. E. Evans, K. Kelsey, and A. Drewnowski, "Clarifying concepts about macronutrients' effects on satiation and satiety," Journal of the American Dietetic Association, vol. 104, no. 7, pp. 1151-1153, 2004.

[10] D. M. Mourao, J. Bressan, W. W. Campbell, and R. D. Mattes, "Effects of food form on appetite and energy intake in lean and obese young adults," International Journal of Obesity, vol. 31, no. 11, pp. 1688-1695, 2007.

[11] D. Paddon-Jones, E. Westman, R. D. Mattes, R. R. Wolfe, A. Astrup, and M. Westerterp-Plantenga, "Protein, weight management, and satiety," American Journal of Clinical Nutrition, vol. 87, no. 5, pp. 1558S-1561S, 2008.

[12] A. J. Wanders, J. J. G. C. van den Borne, C. de Graaf et al., "Effects of dietary fibre on subjective appetite, energy intake and body weight: a systematic review of randomized controlled trials," Obesity Reviews, vol. 12, no. 9, pp. 724-739, 2011.

[13] H. J. Leidy, N. S. Carnell, R. D. Mattes, and W. W. Campbell, "Higher protein intake preserves lean mass and satiety with weight loss in pre-obese and obese women," Obesity, vol. 15, no. 2, pp. 421-429, 2007.
[14] D. S. Weigle, P. A. Breen, C. C. Matthys et al., "A highprotein diet induces sustained reductions in appetite, ad libitum caloric intake, and body weight despite compensatory changes in diurnal plasma leptin and ghrelin concentrations," American Journal of Clinical Nutrition, vol. 82, no. 1, pp. 4148, 2005.

[15] A. M. Johnstone, G. W. Horgan, S. D. Murison, D. M. Bremner, and G. E. Lobley, "Effects of a high-protein ketogenic diet on hunger, appetite, and weight loss in obese men feeding ad libitum," American Journal of Clinical Nutrition, vol. 87, no. 1, pp. 44-55, 2008.

[16] M. Veldhorst, A. Smeets, S. Soenen et al., "Protein-induced satiety: effects and mechanisms of different proteins," Physiology and Behavior, vol. 94, no. 2, pp. 300-307, 2008.

[17] M. S. Westerterp-Plantenga, A. Nieuwenhuizen, D. Tomé, S. Soenen, and K. R. Westerterp, "Dietary protein, weight loss, and weight maintenance," Annual Review of Nutrition, vol. 29, pp. 21-41, 2009.

[18] N. C. Howarth, E. Saltzman, and S. B. Roberts, "Dietary fiber and weight regulation," Nutrition Reviews, vol. 59, no. 5, pp. 129-139, 2001.

[19] T. L. Halton and F. B. Hu, "The effects of high protein diets on thermogenesis, satiety and weight loss: a critical review," Journal of the American College of Nutrition, vol. 23, no. 5, pp. 373-385, 2004.

[20] J. L. Slavin, "Dietary fiber and body weight," Nutrition, vol. 21, no. 3, pp. 411-418, 2005.

[21] N. P. Hays, G. P. Bathalon, M. A. McCrory, R. Roubenoff, R. Lipman, and S. B. Roberts, "Eating behavior correlates of adult weight gain and obesity in healthy women aged 55-65 y," American Journal of Clinical Nutrition, vol. 75, no. 3, pp. 476-483, 2002.

[22] V. Provencher, V. Drapeau, A. Tremblay, J. P. Després, and S. Lemieux, "Eating behaviors and indexes of body composition in men and women from the Québec family study," Obesity Research, vol. 11, no. 6, pp. 783-792, 2003.

[23] J. S. Savage, L. Hoffman, and L. L. Birch, "Dieting, restraint, and disinhibition predict women's weight change over $6 y$," American Journal of Clinical Nutrition, vol. 90, no. 1, pp. 3340, 2009.

[24] K. Elfhag and S. Rössner, "Who succeeds in maintaining weight loss? A conceptual review of factors associated with weight loss maintenance and weight regain," Obesity Reviews, vol. 6, no. 1, pp. 67-85, 2005.

[25] A. J. Stunkard and S. Messick, "The three-factor eating questionnaire to measure dietary restraint, disinhibition and hunger," Journal of Psychosomatic Research, vol. 29, no. 1, pp. 71-83, 1985.

[26] P. J. Teixeira, M. N. Silva, S. R. Coutinho et al., "Mediators of weight loss and weight loss maintenance in middle-aged women," Obesity, vol. 18, no. 4, pp. 725-735, 2010.

[27] F. Bellisle, "Why should we study human food intake behaviour?" Nutrition, Metabolism and Cardiovascular Diseases, vol. 13, no. 4, pp. 189-193, 2003.

[28] N. Vogels and M. S. Westerterp-Plantenga, "Successful longterm weight maintenance: a 2-year follow-up," Obesity, vol. 15, no. 5, pp. 1258-1266, 2007.

[29] H. Konttinen, S. Männistö, S. Sarlio-Lähteenkorva, K. Silventoinen, and A. Haukkala, "Emotional eating, depressive symptoms and self-reported food consumption. A populationbased study," Appetite, vol. 54, no. 3, pp. 473-479, 2010.

[30] A. M. Keränen, M. J. Savolainen, A. H. Reponen et al., "The effect of eating behavior on weight loss and maintenance 
during a lifestyle intervention," Preventive Medicine, vol. 49, no. 1 , pp. 32-38, 2009.

[31] P. J. Teixeira, M. N. Silva, S. R. Coutinho et al., "Mediators of weight loss and weight loss maintenance in middle-aged women," Obesity, vol. 18, no. 4, pp. 725-735, 2010.

[32] B. Benelam, "Satiation, satiety and their effects on eating behaviour," Nutrition Bulletin, vol. 34, no. 2, pp. 126-173, 2009.

[33] J. Blundell, C. de Graaf, T. Hulshof et al., "Appetite control: methodological aspects of the evaluation of foods," Obesity Reviews, vol. 11, no. 3, pp. 251-270, 2010.

[34] M. Lyly, N. Ohls, L. Lähteenmäki et al., "The effect of fibre amount, energy level and viscosity of beverages containing oat fibre supplement on perceived satiety," Food and Nutrition Research, vol. 54, article 2149, 2010.

[35] T. V. E. Kral and B. J. Rolls, "Energy density and portion size: their independent and combined effects on energy intake," Physiology and Behavior, vol. 82, no. 1, pp. 131-138, 2004.

[36] D. Frankenfield, L. Roth-Yousey, and C. Compher, "Comparison of predictive equations for resting metabolic rate in healthy nonobese and obese adults: a systematic review," Journal of the American Dietetic Association, vol. 105, no. 5, pp. 775-789, 2005.

[37] A. Astrup, P. C. Gøtzsche, K. van de Werken et al., "Metaanalysis of resting metabolic rate in formerly obese subjects," American Journal of Clinical Nutrition, vol. 69, no. 6, pp. 11171122, 1999.

[38] J. Westenhoefer, A. J. Stunkard, and V. Pudel, "Validation of the flexible and rigid control dimensions of dietary restraint," International Journal of Eating Disorders, vol. 26, no. 1, pp. 53 64, 1999.

[39] T. Van Strien, J. E. R. Frijters, G. P. A. Bergers, and P. B. Defares, "The Dutch eating behavior questionnaire (DEBQ) for assessment of restrained, emotional, and external eating behavior," International Journal of Eating Disorders, vol. 5, no. 2, pp. 295-315, 1986.

[40] J. Gormally, S. Black, S. Daston, and D. Rardin, "The assessment of binge eating severity among obese persons," Addictive Behaviors, vol. 7, no. 1, pp. 47-55, 1982.

[41] D. Goldberg and P. Williams, A Users Guide to the General Health Questionnaire, NFERNELSON Publishing Co.Ltd, Windsor, Berkshire, UK, 1988.

[42] F. M. Sacks, G. A. Bray, V. J. Carey et al., "Comparison of weight-loss diets with different compositions of fat, protein, and carbohydrates," New England Journal of Medicine, vol. 360, no. 9, pp. 859-873, 2009.

[43] R. Dalle Grave, S. Calugi, F. Corica, S. Di Domizio, and G. Marchesini, and QUOVADIS Study Group, "Psychological variables associated with weight loss in obese patients seeking treatment at medical centers," Journal of the American Dietetic Association, vol. 109, no. 12, pp. 2010-2016, 2009.

[44] C. A. Timko and J. Perone, "Rigid and flexible control of eating behavior in a college population," Eating Behaviors, vol. 6, no. 2, pp. 119-125, 2005.

[45] F. Johnson, M. Pratt, and J. Wardle, "Dietary restraint and selfregulation in eating behavior," International Journal of Obesity, vol. 36, no. 5, pp. 665-674, 2012.

[46] M. T. McGuire, R. W. Jeffery, S. A. French, and P. J. Hannan, "The relationship between restraint and weight and weightrelated behaviors among individuals in a community weight gain prevention trial," International Journal of Obesity, vol. 25, no. 4, pp. 574-580, 2001.

[47] V. Drapeau, V. Provencher, S. Lemieux, J. P. Després, C. Bouchard, and A. Tremblay, "Do 6-y changes in eating behaviors predict changes in body weight? Results from the Quebec Family Study," International Journal of Obesity, vol. 27, no. 7, pp. 808-814, 2003.

[48] A. DelParigi, K. Chen, A. D. Salbe et al., "Successful dieters have increased neural activity in cortical areas involved in the control of behavior," International Journal of Obesity, vol. 31, no. 3, pp. 440-448, 2007.

[49] M. Hollmann, L. Hellrung, B. Pleger et al., "Neural correlates of the volitional regulation of the desire for food," International Journal of Obesity, vol. 36, no. 5, pp. 648-655, 2012.

[50] A. Bandura, "Self-efficacy: toward a unifying theory of behavioral change," Psychological Review, vol. 84, no. 2, pp. 191-215, 1977.

[51] A. L. Palmeira, P. J. Teixeira, T. L. Branco et al., "Predicting short-term weight loss using four leading health behavior change theories," International Journal of Behavioral Nutrition and Physical Activity, vol. 4, article no. 14, 2007.

[52] N. Hankonen, M. Vollmann, B. Renner, and P. Absetz, "What is setting the stage for abdominal obesity reduction? A comparison between personality and health-related social cognitions," Journal of Behavioral Medicine, vol. 33, no. 5, pp. 415-422, 2010.

[53] P. J. Teixeira, H. Patrick, and J. Mata, "Why we eat what we eat: the role of autonomous motivation in eating behaviour regulation," Nutrition Bulletin, vol. 36, no. 1, pp. 102-107, 2011.

[54] A. Due, S. Toubro, A. R. Skov, and A. Astrup, "Effect of normal-fat diets, either medium or high in protein, on body weight in overweight subjects: a randomised 1-year trial," International Journal of Obesity, vol. 28, no. 10, pp. 1283-1290, 2004.

[55] M. P. G. M. Lejeune, E. M. R. Kovacs, and M. S. WesterterpPlantenga, "Additional protein intake limits weight regain after weight loss in humans," British Journal of Nutrition, vol. 93, no. 2, pp. 281-289, 2005.

[56] T. M. Larsen, S. M. Dalskov, M. van Baak et al., "Diets with high or low protein content and glycemic index for weightloss maintenance," New England Journal of Medicine, vol. 363, no. 22, pp. 2102-2113, 2010.

[57] M. P. G. M. Lejeune, K. R. Westerterp, T. C. M. Adam, N. D. Luscombe-Marsh, and M. S. Westerterp-Plantenga, "Ghrelin and glucagon-like peptide 1 concentrations, 24-h satiety, and energy and substrate metabolism during a high-protein diet and measured in a respiration chamber," American Journal of Clinical Nutrition, vol. 83, no. 1, pp. 89-94, 2006.

[58] A. Marinilli Pinto, A. A. Gorin, H. A. Raynor, D. F. Tate, J. L. Fava, and R. R. Wing, "Successful weight-loss maintenance in relation to method of weight loss," Obesity, vol. 16, no. 11, pp. 2456-2461, 2008. 


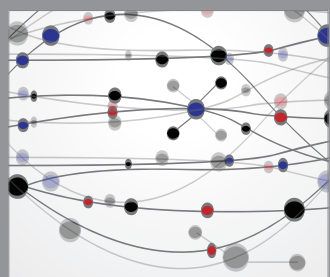

The Scientific World Journal
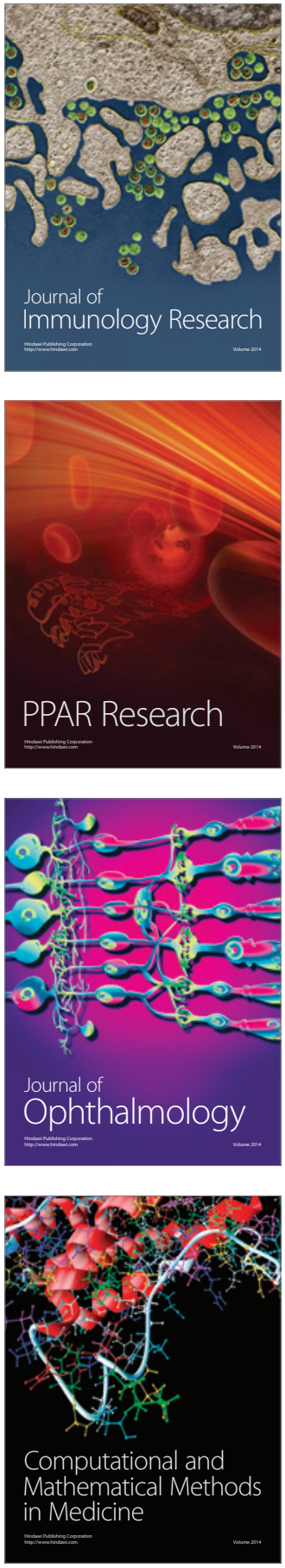

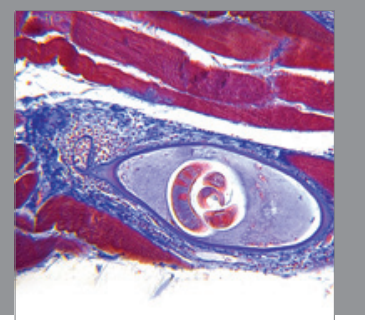

Gastroenterology

Research and Practice
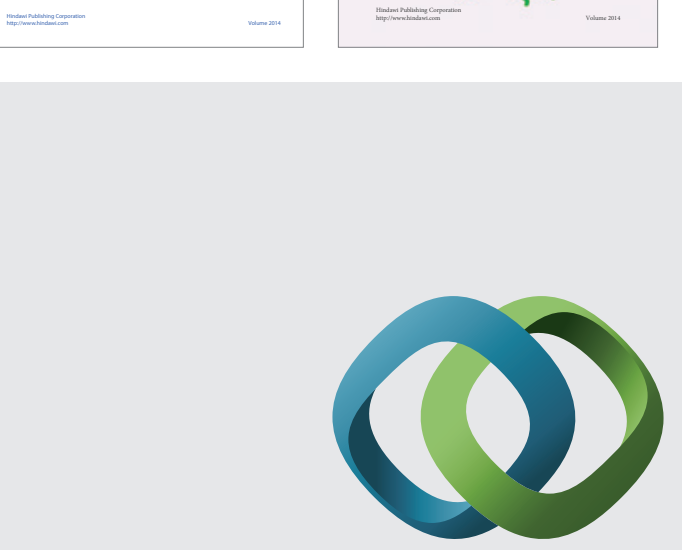

\section{Hindawi}

Submit your manuscripts at

http://www.hindawi.com
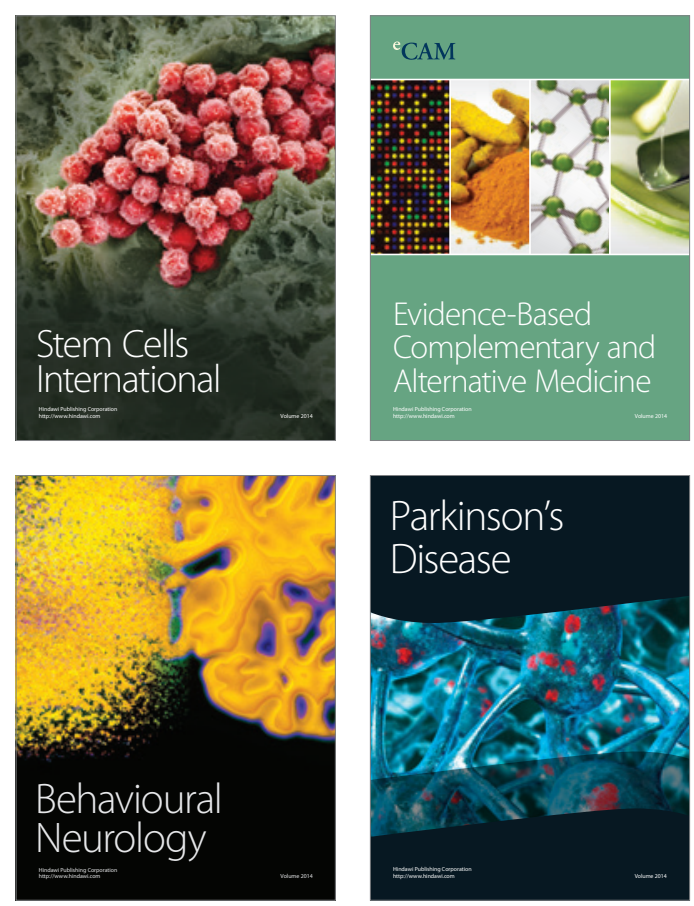

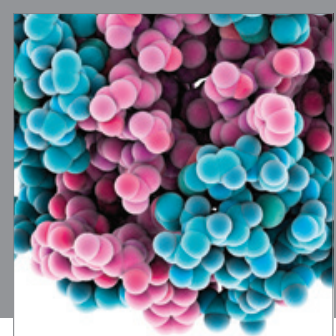

Journal of
Diabetes Research

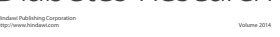

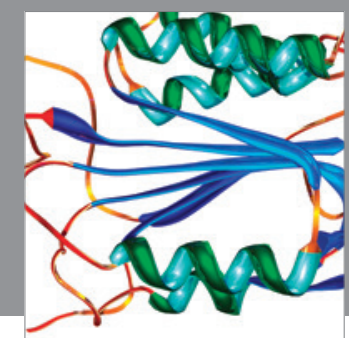

Disease Markers
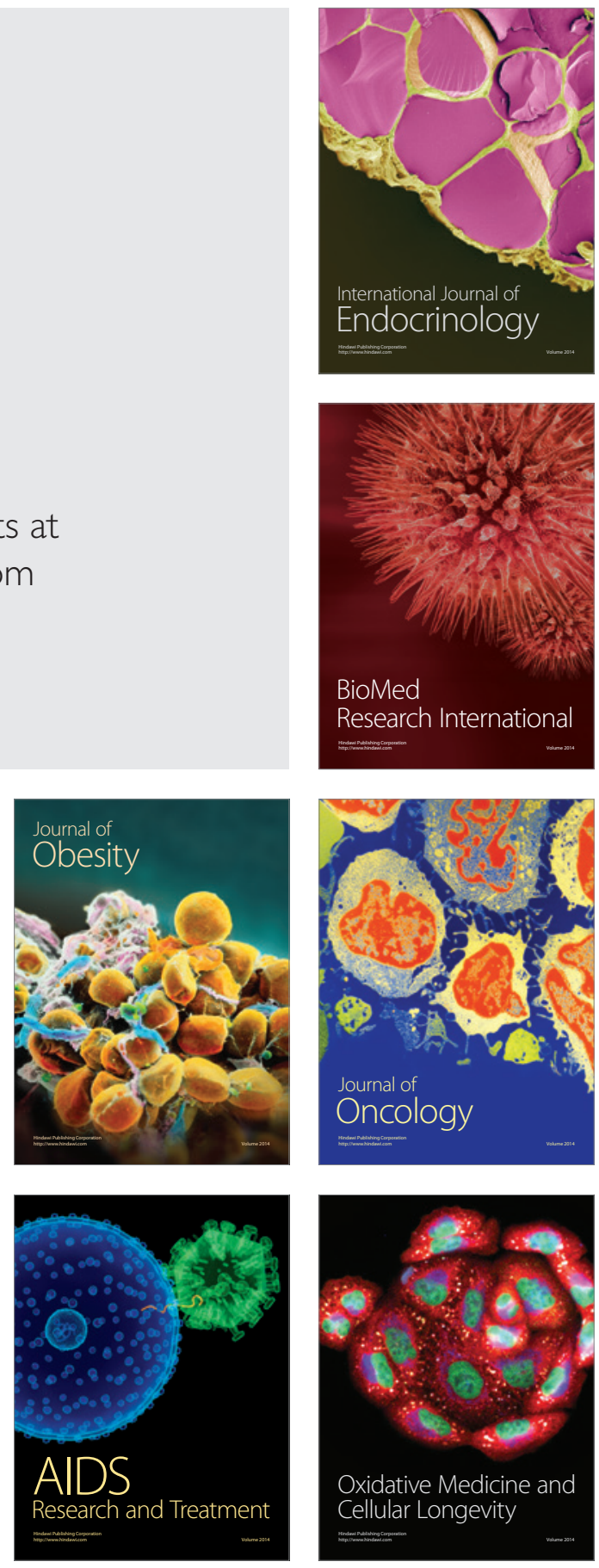